\title{
Ambientes protegidos e substratos para mudas de bocaiuva oriundas do campo
}

\author{
Alexandre de Araújo Áscoli ${ }^{1}$, Amanda Casagrande Pereira ${ }^{1}$, Edilson Costa $^{1}$, Marçal Henrique \\ Amici Jorge $^{2}$, Wilson Itamar Maruyama ${ }^{1}$
}

\author{
${ }^{1}$ Universidade Estadual de Mato Grosso do Sul , Agronomia, Unidade de Cassilândia, Mato Grosso do Sul, Brasil. E-mail: \\ aaascoli@yahoo.com.br, amanda_tanabi@hotmail.com, mestrine@uems.br, wilsonmaruyama@uems.br \\ ${ }^{2}$ Embrapa Hortaliças, Brasília, DF, Brasil. E-mail: marcal.jorge@embrapa.br
}

Recebido: 13/08/2015; Aceito: 18/09/2015

\section{RESUMO}

A bocaiuva é espécie promissora para produção de alimentos e biodiesel; tecnologias de formação de mudas ajudam toda a cadeia produtiva desta espécie. O objetivo foi avaliar o pegamento e o crescimento de mudas de bocaiuva oriundas do campo, em diferentes substratos e ambientes protegidos. Foram avaliados dois ambientes: telado agrícola com tela aluminizada na cobertura e laterais com tela preta; telado agrícola com tela preta em toda sua extensão. Foram testados os substratos Bioplant ${ }^{\circledR} ; 0 \%$ de esterco bovino $+70 \%$ de solo $+30 \%$ de areia; $10 \%$ de esterco bovino $+60 \%$ de solo $+30 \%$ de areia; $20 \%$ de esterco bovino $+50 \%$ de solo $+30 \%$ de areia; $30 \%$ de esterco bovino $+40 \%$ de solo $+30 \%$ de areia. Foi adotado o delineamento inteiramente casualizado com 4 repetições de 10 plantas. Aos 90 e 150 dias após o transplante foi avaliada a porcentagem de sobrevivência. Aos 150 dias também foram avaliadas as fitomassas secas. Foram alcançados níveis de pegamento de $81,25 \%$ das mudas de bocaiuva oriundas do campo. Todos os substratos testados foram propícios ao pegamento e ao crescimento das mudas. $\mathrm{O}$ ambiente de tela aluminizada na cobertura e tela preta nas laterais formaram as melhores mudas.

Palavras-chave: Acrocomia aculeata, Ambiência vegetal, Tecnologias para mudas.

\section{Protected environments and substrates for bocaiuva seedlings coming from field}

\section{ABSTRACT}

The bocaiuva is promising species for food production and biodiesel, and technologies for seedlings help the entire production chain of this species. The objective was to evaluate the fixation and growth of bocaiuva seedlings in different substrates and protected environments. Two environments were evaluated: agricultural screened with aluminized screen on the roof and sides with black screen; agricultural screened with black screen in all its extension. The substrates tested were: Bioplant ${ }^{\circledR} ; 0 \%$ cattle manure $+70 \%$ soil $+30 \%$ sand; $10 \%$ cattle manure + $60 \%$ soil $+30 \%$ sand; $20 \%$ cattle manure $+50 \%$ soil $+30 \%$ sand; $30 \%$ cattle manure $+40 \%$ soil $+30 \%$ sand. It was adopted a completely randomized design with four replications of 10 plants. At 90 and 150 days after transplanting the percentage of survival was evaluated. At 150 days dry phytomass were also evaluated. Fixation levels $81.25 \%$ were achieved for bocaiuva seedlings coming from the field. All substrates tested were favorable to fixation and growth of seedlings. The aluminized screen environment in coverage and black screen on the sides formed the best seedlings.

Key-words: Acrocomia aculeata, Environments, Technologies for seedlings. 


\section{Introdução}

No Brasil, a bocaiuva (Acrocomia aculeata) é considerada como a palmeira de maior dispersão com ocorrência de povoamentos naturais em quase todo território. Entretanto, as maiores concentrações estão localizadas em Minas Gerais, Goiás, Mato Grosso e Mato Grosso do Sul, sendo bastante espalhadas pelas áreas de Cerrado (SILVA et al., 1994) e, também, muito encontradas no Pantanal.

O uso dos recursos da bocaiuva são muito diversificados sendo considerada de grande importância na alimentação de equinos e bovinos durante a seca no Pantanal. Por possuir alto valor proteico, quantidade satisfatória de vitamina A, valor energético elevado, é muito utilizada na produção de farinha e iguarias culinárias (sorvetes, geleias, iogurtes, bolos, etc.), onde tais produtos já estão ganhando reconhecimento no mercado, além de sua utilização na indústria farmacêutica e de cosméticos.

A etapa de produção de mudas é fase fundamental para obtenção de uniformidade nas plantas. Nesta fase o tipo de substrato, ambiente protegido, volume de recipiente, irrigação, adubação e manejo correto da cultura propiciam condições para obtenção de plantas com elevada qualidade para o sucesso do cultivo a campo.

Existem inúmeras possibilidades de constituição/construção de ambientes protegidos para a produção vegetal, com diversas configurações (tipo arco, tipo capela, viveiros com fechamentos laterais de diversas inclinações etc), vários materiais estruturais (aço, madeira, concreto etc), diversos materiais de cobertura e de proteção lateral (telas de sombreamento de diversas cores e filmes de polietileno de diversas espessuras) e custos diferenciados em função das tecnologias empregadas. Em estruturas de aço galvanizado, nos últimos anos, se observou menor custo de construção em viveiros telados quando comparados às estufas plásticas e às casas de vegetação climatizadas. Salienta-se que a escolha da estrutura e seus materiais constituintes não depende apenas do custo, mas principalmente, do cultivo a ser realizado.

Estudos com produção de mudas de frutíferas testando ambientes de cultivo e substratos (COSTA et al., 2010; COSTA et al. 2011), revelam que a interação e ação conjunta desses dois fatores propiciam melhores condições para o crescimento e desenvolvimento adequado da planta, refletindo em desempenho superior da muda (o vigor e a robustez) e propiciando cultivos comerciais com elevado potencial para produção de frutos.

A disponibilidade de radiação solar global (RSG) influi diretamente na disponibilidade de radiação fotossinteticamente ativa (RFA). A RFA ocupa o espectro de comprimento de onda visível, que varia de
400 a $700 \mathrm{~nm}$ e responsável pela excitação das moléculas de clorofila para realização da fotossíntese. Desta forma, diferentes níveis de sombreamento promovem diferenciação no crescimento de mudas, como exemplo na Sclerolobium paniculatum (FELFILI et al., 1999) e da maioria de outras espécies.

A formação das mudas em ambiente protegido é realizada em recipientes contendo substratos. O substrato tem a função de fixação e nutrição inicial da planta assegurando as condições físico-químicas que favoreçam a emergência de plântulas, crescimento e desenvolvimento radicular (AMMA; CASCARDO, 1994). A variação na composição destes substratos pode resultar em problemas, podendo ocorrer a não germinação das sementes ou formação de plantas anormais (MINAMI, 1995). A disponibilidade do substrato na região de produção (subprodutos de outros setores do agronegócio) diminui custos com a produção da muda, porém Pereira et al. (2008) ressaltam a importância de esterilidade biológica do material utilizado como qualidade desejável em um substrato.

$\mathrm{Na}$ literatura são escassos os trabalhos com ambientes protegidos e substratos na formação de mudas de bocaiuva. Costa et al. (2014) observaram que substrato constituído de ramas de mandioca triturada e adubada, não formaram mudas de bocaiuva de elevada qualidade e verificaram, também, que substratos que continham esterco bovino foram favoráveis a formação das mesmas. Os mesmos autores obtiveram melhores mudas em viveiro de tela aluminizada (cobertura e frontais), quando comparada a estufa coberta com filme de polietileno de baixa densidade e viveiro telado com tela preta.

O objetivo foi avaliar o pegamento e o crescimento de mudas de bocaiuva oriundas do campo, em diferentes ambientes protegidos substratos.

\section{Material e Métodos}

Os experimentos com pegamento e crescimento de mudas bocaiuva, oriundas do campo, foram conduzidos na Universidade Estadual de Mato Grosso do Sul (UEMS), Unidade Universitária de Cassilândia-MS. O local possui latitude de $19^{\circ} 07^{\prime} 21^{\prime \prime} \mathrm{S}$, longitude de 51\%43'15" W e altitude de 516 m (Estação automática CASSILANDIA-A742).

Foram utilizados dois ambientes: ( $1^{\circ}$ ambiente) telado agrícola, possuindo $8,00 \mathrm{~m}$ de largura por 18,00 $\mathrm{m}$ de comprimento e 4,00 $\mathrm{m}$ de altura, fechamento em $90^{\circ}$ graus, com tela preta nas laterais e aluminizada na cobertura, ambas de $50 \%$ de sombreamento (A1); ( $2^{\circ}$ ambiente) telado agrícola possuindo $8,00 \mathrm{~m}$ de largura por $18,00 \mathrm{~m}$ de comprimento e $3,50 \mathrm{~m}$ de altura, fechamento em $45^{\circ}$ graus, com tela preta nas laterais e cobertura de $50 \%$ de sombreamento (A2). 
No interior dos ambientes protegidos foram testados os substratos (S1) Bioplant ${ }^{\circledR}$; (S2) $0 \%$ de esterco bovino $+70 \%$ de solo $+30 \%$ de areia de estrada fina e lavada; (S3) $10 \%$ de esterco bovino $+60 \%$ de solo $+30 \%$ de areia; (S4) $20 \%$ de esterco bovino $+50 \%$ de solo $+30 \%$ de areia; (S5) 30\% de esterco bovino $+40 \%$ de solo + $30 \%$ de areia.

Por não haver repetições dos ambientes de cultivo, cada um foi considerado um experimento. Para cada ambiente de cultivo foi adotado o delineamento experimental inteiramente casualizado para avaliação dos substratos, com 4 repetições de 10 plantas. Os ambientes foram avaliados pela análise de grupos de experimentos (BANZATTO; KRONKA, 2013). Nas Tabelas 1 e 2 estão as análises do solo de barranco e do esterco bovino, respectivamente.

O solo foi coletado em barranco da região (Tabela 1) e o esterco bovino foi adquirido em frigorífico e compostado por 45 dias (Tabela 2). A irrigação foi realizada com rega manual procurando não encharcar os substratos.

As plantas foram coletadas de áreas de pastagens e de campo do município de Corumbá-MS nos dias 4 e 5 de novembro de 2015. No dia 06 de novembro de 2015 as plantas foram podadas e padronizadas com $10 \mathrm{~cm}$ de altura e transplantadas para saquinhos de polietileno de $15,0 \times 25,0 \mathrm{~cm}(1,8 \mathrm{~L})$.
No interior dos ambientes protegidos foram monitoradas as temperaturas do ar $\left({ }^{\circ} \mathrm{C}\right)$, as umidades relativas do ar (\%), as radiações solar global $\left(\mathrm{W} \mathrm{m}^{-2}\right)$, as radiações fotossinteticamente ativa total e difusa $(\mu \mathrm{mol}$ $\left.\mathrm{m}^{-2} \mathrm{~s}^{-1}\right)$. Os dados micrometeorológicos no interior dos ambientes protegidos foram realizadas por sensores específicos, acoplados a um "datalloger" marca Delta $\mathrm{T}$ Devices, modelo GP2, instalados no centro geométrico do ambiente. O sistema foi programado para realizar leituras em intervalos de 10 segundos, com médias a cada minuto. Para as radiações, a média diária foi calculada no horário das 7 às 18 horas (Tabela 3 ).

Para o ambiente externo os valores de temperatura do ar, umidades relativas do ar e radiação solar global foram adquiridas da plataforma automática de coleta de dados de Cassilândia (A742, INMET-SONABRA) (Tabela 3), a qual não fornece as radiações fotossinteticamente ativa. Os dados micrometeorológicos foram coletados de 06/11/2014 a 06/02/2015.

A precipitação pluviométrica durante a condução dos experimentos - novembro de 2014 (181,8 mm), dezembro de 2014 (159,8 mm), janeiro de 2015 (88,2 $\mathrm{mm})$, fevereiro de 2015 (220,6 mm) e março de 2015 $(145,4 \mathrm{~mm})$ foram obtidas da plataforma automática de coleta de dados de Cassilândia (A742, INMETSONABRA).

Tabela 1. Análise do solo utilizado no experimento. Cassilândia, MS, 2014-2015.

\begin{tabular}{|c|c|c|c|c|c|c|}
\hline $\begin{array}{l}P_{\text {resina }} \\
\mathrm{mg} \mathrm{dm}^{-3}\end{array}$ & $\mathrm{~K}$ & $\mathrm{Ca}$ & $\mathrm{Mg}$ & SB & CTC & V\% \\
\hline 4 & $0, \overline{6}$ & 7 & $\overline{3}$ & 11 & 50 & 22 \\
\hline $\begin{array}{l}\text { pH } \\
\text { água }\end{array}$ & $\begin{array}{l}\mathrm{MO} \\
\mathrm{g} \mathrm{dm}^{-3}\end{array}$ & B & $\mathrm{Cu}$ & $\mathrm{Fe}$ & $\mathrm{Mn}$ & $\mathrm{Zn}$ \\
\hline $\begin{array}{l}4,6 \\
\text { nat }\end{array}$ & 6 & $\overline{0}, \overline{21}$ & 0,5 & 15 & 8,3 & 0,1 \\
\hline
\end{tabular}

MO = matéria orgânica.

Tabela 2. Análise do esterco bovino utilizado no experimento. Cassilândia, MS, 2014-2015.

\begin{tabular}{|c|c|c|c|c|c|c|c|}
\hline $\mathrm{N}$ & $\mathrm{P}_{2} \mathrm{O}_{5}$ & $\mathrm{~K}_{2} \mathrm{O}$ & $\mathrm{Ca}$ & $\mathrm{Mg}$ & $S$ & $\mathrm{U}-65^{\circ} \mathrm{C}$ & $\mathrm{C}$ \\
\hline 0,9 & 0,3 & 0,1 & 0,3 & 0,1 & 0,2 & 2,0 & 11,0 \\
\hline $\mathrm{Na}$ & $\mathrm{Cu}$ & $\mathrm{Fe}$ & $\mathrm{Mn}$ & $\mathrm{Zn}$ & $\mathrm{C} / \mathrm{N}$ & $\mathrm{pH}$ & MO \\
\hline 624 & 18 & $\begin{array}{r}\text { natural } \\
12103\end{array}$ & 204 & 53 & $12 / 1$ & $\begin{array}{l}\mathrm{CaCl}_{2} \\
5,3\end{array}$ & $\begin{array}{l}* * \% \text { ao natural } \\
20,0\end{array}$ \\
\hline
\end{tabular}

$\mathrm{U}=$ umidade; $\mathrm{MO}$ = matéria orgânica; $\mathrm{C} / \mathrm{N}$ = relação carbono e nitrogênio.

Tabela 3. Médias de temperatura $\left({ }^{\circ} \mathrm{C}\right)$, umidade relativa $(\%)$, radiação solar global $\left(\mathrm{W} \mathrm{m}^{-2}\right)$, radiação fotossinteticamente ativa total $\left(\mu \mathrm{mol} \mathrm{m} \mathrm{s}^{-1}\right)$ e radiação fotossinteticamente ativa difusa $\left(\mu \mathrm{mol} \mathrm{m} \mathrm{s}^{-1}\right)$. Cassilândia-MS, 2014-2015.

\begin{tabular}{|c|c|c|c|}
\hline Variáveis micrometeorológicos & Tela Aluminizado & $\begin{array}{l}\text { Tela } \\
\text { Preta }\end{array}$ & Externo \\
\hline Temperatura $\left({ }^{\circ} \mathrm{C}\right)$ & 25,36 & 25,48 & 25,84 \\
\hline Umidade relativa (\%) & 72,89 & 69,11 & 70,48 \\
\hline Radiação solar global ( $\mathrm{W} \mathrm{m}^{-2}$ ) & 203,24 & 187,48 & 499,59 \\
\hline Radiação fotossinteticamente ativa total $\left(\mu \mathrm{mol} \mathrm{m}{ }^{-2} \mathrm{~s}^{-1}\right)$ & 399,07 & 399,85 & - \\
\hline Radiação fotossinteticamente ativa difusa $\left(\mu \mathrm{mol} \mathrm{m} \mathrm{s}^{-1}\right)$ & 218,74 & 166,03 & - \\
\hline
\end{tabular}


Aos 90 e 150 dias após o transplante foram avaliadas as porcentagens de sobrevivência (pegamento), designadas por PORSO1 e PORSO 2. Aos 150 dias, também, foram avaliadas a fitomassa seca da parte aérea (MSA) e a fitomassa seca do sistema radicular (MSR). Foram determinadas a fitomassa seca total (MST) e a relação entre a fitomassa seca aérea e radicular (RMS).

Os dados de porcentagens passaram por transformação em arc sen raiz (x/100). Os dados foram submetidos à análise de variância (teste F) e as médias comparadas pelo teste de Tukey para os substratos e pelo próprio teste $\mathrm{F}$ para os ambientes de cultivo, ambos a 5\% de probabilidade com o software Sisvar.

\section{Resultados e Discussão}

Para as variáveis analisadas a relação entre os quadrados médios dos resíduos (RQMR) foi menor que 7, permitindo a realização da análise conjunta dos experimentos (BANZATTO; KRONKA, 2013) e comparação dos ambientes. Não se verificou interação entre ambientes e substratos nas variáveis testadas, procedendo a análise individual dos fatores. Na Tabela 4 estão explicitados os resultados da porcentagem de sobrevivências das mudas de bocaiuva aos 90 e 150 dias após o transplante.

Não foram verificadas diferenças para a porcentagem de sobrevivência das mudas de bocaiuva nos tratamentos utilizados (Tabela 4). Aos 90 e 150 dias após o transplante (DAT) a porcentagem média de sobrevivência no ambiente com tela aluminizada foi de 78,00 e $72,00 \%$ e no ambiente com tela preta foi de 85,25 e 75,00, com média geral de 81,63 e 73,66\%, respectivamente. Mesmo com maior quantidade de disponibilidade de radiação solar global, radiação fotossinteticamente ativa difusa e umidade relativa no ambiente de tela aluminizada (Tabela 3) não se verificou diferenças na porcentagem de sobrevivência das mudas de bocaiuva nos ambientes testados (Tabela
4). Costa et al. (2014) por sua vez, obtiveram melhores mudas de bocaiuva em tela aluminizada. Meirelles et al. (2007) observaram que as malhas de sombreamento (preta de 50\%; preta de $80 \%$; azul de $50 \%$ e vermelha de 50\%) não influenciaram o desenvolvimento de mudas de palmeira-ráfia, semelhante ao verificado na sobrevivência das mudas de bocaiuva no presente estudo (Tabela 4).

A porcentagem de sobrevivência das mudas aos $90 \mathrm{e}$ 150 DAT no substrato comercial (S1) Bioplant® foram de 86,88 e $80,63 \%$, no substrato (S2) com " $0 \%$ de esterco bovino $+70 \%$ de solo $+30 \%$ de areia" foram de 81,25 e $65,18 \%$, no substrato (S3) com " $10 \%$ de esterco bovino $+60 \%$ de solo $+30 \%$ de areia" foram de 81,25 e $66,43 \%$, no substrato (S4) com " $20 \%$ de esterco bovino $+50 \%$ de solo $+30 \%$ de areia" foram de 81,25 e $81.25 \%$ e no substrato (S5) com " $30 \%$ de esterco bovino $+40 \%$ de solo $+30 \%$ de areia" foram de 76,25 e $65 \%$, com média geral de 81,38 e $71,70 \%$, respectivamente (Tabela 4).

Tanto o substrato comercial quanto os substratos alternativos, com ou sem esterco bovino, foram favoráveis à sobrevivência das mudas de bocaiuva (Tabela 4), contudo Costa et al. (2014) observaram que substrato sem esterco bovino, constituído de ramas de mandioca triturada e adubada, não formaram mudas de bocaiuva de elevada qualidade. Os mesmos autores ainda verificaram que todos os substratos que continham esterco bovino foram indicados para a formação de mudas de bocaiuva, assim como o verificado por Luz et al. (2011) para mudas de Palmeira-ráfia [Rhapis excelsa (Thunb.) A. Henry ex Rehder], estando de acordo com os resultados do presente trabalho. A qualidade química dos substratos (Tabelas 1 e 2) não foi fator decisivo na sobrevivência das mudas (Tabela 4), similar ao observado por Meirelles et al. (2007) que apontaram não haver efeito de adubação foliar no desenvolvimento de mudas de palmeira-ráfia com altura superior a $35 \mathrm{~cm}$.

Tabela 4. Porcentagem de sobrevivência (PORSO) de mudas de bocaiuva em diferentes ambientes protegidos e substratos aos 90 (PORSO 1) e 150 (PORSO 2) dias após o transplante. Cassilândia, MS, 2014-2015.

\begin{tabular}{lll}
\hline Ambientes & PORSO 1 $(\%)$ & PORSO 2 $(\%)$ \\
\hline (A1) Tela aluminizada & $78,00 \mathrm{a}$ & $72,00 \mathrm{a}$ \\
(A2) Tela preta & $85,25 \mathrm{a}$ & $75,00 \mathrm{a}$ \\
Média & 81,63 & 73,66 \\
\hline Substratos & PORSO 1 $(\%)$ & PORSO 2(\%) \\
\hline (S1) Bioplant ${ }^{\circledR}$ & $86,875 \mathrm{a}$ & $80,63 \mathrm{a}$ \\
(S2) $0 \%$ de esterco bovino $+70 \%$ de solo $+30 \%$ de areia & $81,25 \mathrm{a}$ & $65,18 \mathrm{a}$ \\
(S3) $10 \%$ de esterco bovino $+60 \%$ de solo $+30 \%$ de areia & $81,25 \mathrm{a}$ & $66,43 \mathrm{a}$ \\
(S4) $20 \%$ de esterco bovino $+50 \%$ de solo $+30 \%$ de areia & $81,25 \mathrm{a}$ & $81,25 \mathrm{a}$ \\
(S5) 30\% de esterco bovino $+40 \%$ de solo $+30 \%$ de areia & $76,25 \mathrm{a}$ & $65,00 \mathrm{a}$ \\
Média & 81,38 & 71,70 \\
\hline CV(\%) & 18,24 & 17,36 \\
\hline
\end{tabular}

$\mathrm{CV}=$ coeficiente de variação; Letras iguais não diferem pelo teste de Tukey para os substratos e pelo teste $\mathrm{F}$ para os ambientes, ambos a 5\% de probabilidade. Os dados de porcentagens passaram por transformação em arc sen raiz (x/100). 
Observa-se que houve mortalidade de mudas dos 90 (04/02/2015) para o $150(05 / 04 / 2015)$ DAT. Com as maiores chuvas concentradas em fevereiro $(220,6 \mathrm{~mm})$ se verificava, em muitos dias, o encharcamento dos substratos, o que provavelmente contribuiu para a mortalidade de plantas no referido período, pois em substratos encharcados a difusão de oxigênio é menor, ocorrendo menor disponibilidade do mesmo para o sistema radicular. O tecido radicular, sendo aclorofilado, depende de energia para manutenção de suas células e para processos como absorção de nutriente de forma ativa. Esta energia é obtida pelo catabolismo de compostos como carboidratos por meio de oxidação na presença de oxigênio (respiração) e com o encharcamento, esse processo foi dificultado levando a mortalidade de algumas plantas.

Não houve diferença, tanto nos níveis do fator ambiente, quanto nos níveis do fator substrato, para as variáveis fitomassa seca do sistema radicular (MSR) e relação entre a fitomassa seca aérea e radicular (RMS). Para as variáveis fitomassa seca da parte aérea (MSA) e fitomassa seca total (MST), apenas os níveis dos ambientes apresentaram diferenças (Tabela 5).

As maiores fitomassas aéreas e totais foram observadas no ambiente coberto com tela aluminizada (Tabela 5), estando de acordo com os resultados de Costa et al. (2014) que observaram melhores mudas em telado de tela termorrefletora aluminizada em comparação com a estufa agrícola coberta com polietileno de baixa densidade e com telado de tela preta. Mudas de palmeira conhecida popularmente como carnaúba hospedeira (Copernicia hospita Martius) tiveram maior emergência em casa de vegetação que a pleno sol (OLIVEIRA et al., 2009).

Observa-se nitidamente a influencia do tipo de ambiente protegido sobre o crescimento das mudas de bocaiuva (Tabela 5), em que a maior quantidade de disponibilidade de radiação solar global, radiação fotossinteticamente ativa difusa e umidade relativa no ambiente de tela aluminizada (Tabela 3) propiciaram melhores condições ambientais por favorecer o acumulo de fitomassa decorrente da maior fotossíntese líquida proporcionado nesse ambiente, assim como maior disponibilidade de fotoassimilados para ser investido no crescimento do vegetal.

No presente estudo aos 150 DAT, a MSA e a MST das plantas, no telado aluminizado, foram de 1,388 e 4,132 g (Tabela 5), respectivamente, resultados estes inferiores aos encontrados por Costa et al. (2014) que verificaram valores de MSA de 3,97 g e MST de 5,55g.

Os substratos não diferiram para as variáveis de fitomassas e todos os substratos que continham esterco foram propícios para mudas da bocaiuva, assim como observado e relatado por Costa et al. (2014). A quantidade de nutrientes presentes nos diferentes substratos (Tabela 2 e 3 ) não influenciaram o pegamento (Tabela 4) e o crescimento (Tabela 5) das mudas de bocaiuva oriundas do campo. Para a palmeira carnaúba hospedeira (Copernicia hospita Martius), Oliveira et al. (2009) não observaram diferenças na emergência das plântulas comparando os substratos [areia vermelha + bagana de carnaúba + húmus $(2,5: 2,5: 1$ em volume $)$ e solo + arisco + composto orgânico Polefértil ${ }^{\circledR}(2: 2: 1$ em volume)].

Tabela 5. Fitomassas secas da parte aérea (MSA), radicular (MSR), total (MST) e relação massa seca aérea e radicular (RMS) de mudas de bocaiuva em diferentes ambientes protegidos e substratos aos 150 dias após o transplante. Cassilândia, MS, $2014-2015$.

\begin{tabular}{|c|c|c|c|c|}
\hline Ambientes & $\operatorname{MSA}(\mathrm{g})$ & $\operatorname{MSR}(\mathrm{g})$ & $\operatorname{MST}(\mathrm{g})$ & RMS \\
\hline (A1) Tela aluminizada & $1,388 \mathrm{a}$ & $2,745 \mathrm{a}$ & $4,132 \mathrm{a}$ & $0,506 \mathrm{a}$ \\
\hline (A2) Tela preta & $1,087 \mathrm{~b}$ & $2,328 \mathrm{a}$ & $3,416 \mathrm{~b}$ & $0,467 \mathrm{a}$ \\
\hline Média & 1,237 & 2,54 & 3,774 & 0,486 \\
\hline Substratos & MSA (g) & MSR (g) & MST (g) & RMS \\
\hline (S1) Bioplant ${ }^{\circledR}$ & $0,9890 \mathrm{a}$ & $2,213 \mathrm{a}$ & $3,202 \mathrm{a}$ & $0,447 \mathrm{a}$ \\
\hline (S2) $0 \%$ de esterco bovino $+70 \%$ de solo $+30 \%$ de areia & $1,3589 \mathrm{a}$ & $2,700 \mathrm{a}$ & 4,059 a & $0,503 \mathrm{a}$ \\
\hline (S3) $10 \%$ de esterco bovino $+60 \%$ de solo $+30 \%$ de areia & $1,3554 \mathrm{a}$ & 2,657 a & $4,013 \mathrm{a}$ & $0,510 \mathrm{a}$ \\
\hline (S4) $20 \%$ de esterco bovino $+50 \%$ de solo $+30 \%$ de areia & $1,3097 \mathrm{a}$ & $2,721 \mathrm{a}$ & $4,031 \mathrm{a}$ & $0,481 \mathrm{a}$ \\
\hline (S5) $30 \%$ de esterco bovino $+40 \%$ de solo $+30 \%$ de areia & $1,4532 \mathrm{a}$ & $2,391 \mathrm{a}$ & 3,844 a & $0,608 \mathrm{a}$ \\
\hline Média & 1,2933 & 2,536 & 3,830 & 0,510 \\
\hline $\mathrm{CV}(\%)$ & 27,32 & 29,81 & 25,33 & 30,38 \\
\hline
\end{tabular}

$\mathrm{CV}$ = coeficiente de variação; Letras iguais não diferem pelo teste de Tukey para os substratos e pelo teste $\mathrm{F}$ para os ambientes, ambos a $5 \%$ de probabilidade.

\section{Conclusões}

O ambiente de tela aluminizada na cobertura e tela preta nas laterais formaram as melhores mudas.

Todos os substratos testados foram propícios ao pegamento e ao crescimento das mudas.

Foram alcançados níveis de pegamento de $81,25 \%$ das mudas de bocaiuva oriundas do campo.

\begin{abstract}
Agradecimentos
À CAPES pela bolsa de Mestrado do primeiro. Ao CNPq pela bolsa produtividade do primeiro autor, Proc. $\mathrm{N}^{\mathrm{o}}$ 300829/2012-4. À FUNDECT pelo auxílio à pesquisa, Programa Primeiros Projetos PPP 05/2011, Proc. No 23/200.647/2012. À EMBRAPA pelo auxílio à pesquisa, projeto BOCPAN.
\end{abstract}




\section{Referências Bibliográficas}

AMMA, A. T.; CASCARDO, G. Producción hortícola sin solo, experiências iniciales. Rivista di Agricoltura Subtropicale e Tropicale, Florença-ITA, v. 88, n. 3, p. 559$567,1994$.

BANZATTO, D. A.; KRONKA, S. N. Experimentação agrícola. 4. ed. Jaboticabal-SP: Funep, 2013. 237 p.

COSTA, E.; LEAL, P. A. M.; SASSAQUI, A. R.; GOMES, V. A. Doses de composto orgânico comercial na composição de substratos para a produção de mudas de maracujazeiro em diferentes tipos de cultivo protegido. Engenharia Agrícola, Jaboticabal-SP, v. 30, n. 5, p. 776-787, 2010.

COSTA, E.; LEAL, P. A. M.; MESQUITA, V. A. G.; SASSAQUI, A. R. Efeitos do Organosuper ${ }^{\circledR}$ e do ambiente protegido na formação de mudas de mamoeiro. Engenharia Agrícola, Jaboticabal-SP, v. 31, n. 1, p. 41-55, 2011.

COSTA, E.; MARTINS, R. F.; FARIA, T. A. C.; JORGE, M. H. A.; LEAL, P. A. M. Seedlings of Acrocomia aculeata in diferent substrates and protected environments. Engenharia Agrícola, Jaboticabal-SP, v. 34, n. 3, p. 395-404, 2014.

FELFILI, J. M.; HILGBERT, L. F.; FRANCO, A. C.; SILVA, J. C. S.; REZENDE, A. V.; NOGUEIRA, M. V. P. Comportamento de plântulas de Sclerolobium paniculatum Vog. var. rubinosum (Tul.) Benth. sob diferentes níveis de sombreamento, em viveiro. Revista Brasileira de Botânica, São Paulo-SP, v. 22, n. 2, p. 297-301, 1999.
LUZ, P. B.; PAIVA, P. D. O.; TAVARES, A. R.; KANASHIRO, S.; AGUIAR, F. F. A. Efeito de diferentes substratos e adubação fosfatada no crescimento de mudas de Rhapis excelsa (Thunb.) A. Henry ex Rehder (Palmeira-ráfia). Revista Brasileira de Horticultura Ornamental, Jundiaí-SP, v. 17, n. 1, p. 37-42, 2011.

MEIRELLES, A. J. A.; PAIVA, P. D. O.; OLIVEIRA, M. I.; TAVARES, T. S. Influência de diferentes sombreamentos e nutrição foliar no desenvolvimento de mudas de Palmeiras Ráfia Rhapis excelsa (Thunberg) Henry ex. Rehder. Ciência e Agrotecnologia, Lavras-MG, v. 31, n. 6, p. 1884-1887, 2007.

MINAMI, K. Produção de mudas de alta qualidade em horticultura. São Paulo-SP: Ed. Fundação Salim Sahad Maluf, 1995. 128p.

OLIVEIRA, A. B.; MEDEIROS FILHO, S.; BEZERRA, A. M. E.; BRUNO, R. L. A. Emergência de plântulas de Copernicia Hospita Martius em função do tamanho da semente, do substrato e ambiente. Revista Brasileira de Sementes, Londrina-PR, v. 31, n. 1, p. 281-287, 2009.

PEREIRA, W. E.; SOUSA, G. G.; ALENCAR, M. L.; MENDOÇA, R. M. N; SILVA, G. L. Crescimento de mudas de mamoeiro em substrato contendo caulim. Revista Verde de Agroecologia e Desenvolvimento Sustentável, MossoróRN, v. 3, n. 1, p. 27-35, 2008.

SILVA, J. A.; SILVA, D. B.; JUNQUEIRA, N. T. V.; ANDRADE, L. R. N. Frutas nativas dos cerrados. BrasíliaDF: EMBRAPA-CPAC: EMBRAPA-SPI, 1994. 166 p. 